\title{
Matrix metalloproteinases, synaptic injury, and multiple sclerosis
}

\author{
Arek Szklarczyk ${ }^{1}$ and Katherine Conant ${ }^{2 *}$ \\ 1 Jagiellonian Center of Innovation, Kraków, Poland \\ 2 Department of Neuroscience, Georgetown University, Washington, DC, USA
}

Edited by:

Mark R. Cookson, National Institutes of Health, USA

\section{Reviewed by:}

Isidro Ferrer, University of Barcelona,

Spain

Patricia Coyle, Stony Brook University, USA

\section{${ }^{*}$ Correspondence:}

Katherine Conant, Department of

Neuroscience, Georgetown University,

Room EP-04, New Research Building,

3970 Reservoir Road, Washington,

DC 20007, USA

e-mail: kec84@georgetown.edu
Multiple sclerosis (MS) is a disease of the central nervous system in which immune mediated damage to myelin is characteristic. For an overview of this condition and its pathophysiology, please refer to one of many excellent published reviews (Sorensen and Ransohoff, 1998; Weiner, 2009). To follow, is a discussion focused on the possibility that synaptic injury occurs in at least a subset of patients, and that matrix metalloproteinases (MMPs) play a role in such.

Keywords: matrix metalloproteinase, cadherin, MMP, ICAM, synapse, multiple sclerosis, adhesion molecule

\section{ARCHITECTURE OF THE CENTRAL SYNAPSE}

Synapses are highly dynamic structures through which neurons communicate. Distal terminals of an axon make up the pre-synaptic component of the synapse, while actin rich dendritic spines constitute the post-synaptic component. The action potential is propagated along the axon to terminals, and subsequent changes in intracellular calcium lead to the release of neurotransmitter containing vesicles. Released neurotransmitter crosses the synaptic cleft and binds to specific receptors which are concentrated on dendritic spines. As synapses become stronger, the diameter of dendritic spines may concomitantly enlarge to allow for increased insertion of neurotransmitter receptors.

Synaptic structure is organized through a sequential program that involves specific protein-protein and protein-lipid interactions. While a full discussion of synapse development is beyond the scope of this review, it should be noted that synaptic cell adhesion molecules (CAMs) may contribute to this process. These molecules can also influence the structure and function of preformed synapses. CAMs include cadherins, neurexins, neuroligins, integrins, and immunoglobulin (Ig) superfamily molecules (IgCAMs). Of additional relevance to this review are specific preand post-synaptically localized proteins. Immunostaining can be used to visualize these molecules which including the pre-synaptic protein synaptophysin, and the post-synaptic density protein PSD-95.

\section{SYNAPTIC INJURY AND MS}

Cognitive impairment may occur in association with MS (GonzalezRosa et al., 2006; Schulz et al., 2006). Multiple mechanisms may contribute, including axonal transection (Trapp et al., 1998) and diffuse white matter damage that impairs the connectivity of large scale networks (Audoin et al., 2006; Ranjeva et al., 2006). Gray matter damage may, however, also be important. For example, a recent MRI study showed that neocortical atrophy occurred in the earliest stages of MS and that it was significant even with minimal white matter damage (Iimuro et al., 2003).

Neocortical lesions have been linked to axonal, neuronal, and glial loss (Vercellino et al., 2005; Wegner et al., 2006). Such lesions have also been associated with synaptic elimination. For example, a $47 \%$ decrease in neocortical synaptophysin was noted in one study, and the authors concluded that neocortical lesions might make a major independent contribution to MS pathology (Wegner et al., 2006).

Synaptic damage also occurs in experimental allergic encephalomyelitis (EAE), an animal model of autoimmune demyelination. Analysis of synaptic protein abundance in EAE brains reveals reduced levels of the pre-synaptic proteins synaptophysin and synapsin, and reduced levels of the post-synaptic protein PSD-95. The synaptic injury was linked to infiltrating inflammatory cells (Zhu et al., 2003). The authors of this study hypothesized that disease associated changes in intracellular calcium might have activated the intracellular protease calpain, which is known to target PSD-95 (Lu et al., 2000). In related work, synaptic stripping was described in association with focal cortical inflammation initiated by the intracerebral injection of killed bacteria (BCG). In this model, axosomatic synapses were displaced by activated microglia (Trapp et al., 2007). A summary of relevant studies is shown in Table $\mathbf{1 .}$

\section{MATRIX METALLOPROTEASES- A FAMILY OF ZINC DEPENDENT ENDOPEPTIDASES THAT CAN TARGET VARIED SYNAPTIC SUBSTRATES}

\section{MMPS- AN OVERVIEW}

MMPs are a family of zinc dependent endopeptidases, of which are found in humans. Subsets include the soluble MMPs, at least some of which may be released from vesicular stores. These forms contain a pro- domain, a catalytic domain, and typically, a hemopexin like 
Table 1 | Synaptic injury in MS and relevant disease models.

\begin{tabular}{lll}
\hline Disease/Model & Evidence of synaptic injury & Reference(s) \\
\hline $\begin{array}{ll}\text { Multiple sclerosis } \\
\text { Multiple sclerosis }\end{array}$ & Axonal transection & Trapp et al. (1998) \\
EAE & Reduced synaptophysin as measured by immunoautoradiography & Wegner et al. (2006) \\
& Reduced synaptic density as assessed by Golgi staining and & Rossi et al. (2009) \\
EAE & quantification. Exercise ameliorated this effect & Reduced synaptophysin, synapsin 1 and PSD-95 immunoreactivity \\
that correlated with inflammatory cell infiltration & Zhu et al. (2003) \\
EAE & Inflammatory cell infiltration with AMPA type glutamate receptor \\
& phosphorylation and AMPA receptor-dependent synaptopathy & Centonze et al. (2009) \\
Focal cortical inflammation via & post-synaptic potential (EPSP) recordings \\
intracerebral injection of killed bacteria & Synaptic stripping/microglial cell infiltration of synaptic space \\
\hline
\end{tabular}

domain. The latter may play a role in binding interactions. Activation of secreted soluble MMPs can occur secondary to shedding of the pro- domain, or secondary to events which influence tertiary structure such as oxidation and nitrosylation. Reductions in soluble MMP activity can be affected through binding interactions with endogenous inhibitors, or tissue inhibitors of MMPs (TIMPs). While secreted into the extracellular space, soluble MMPs can interact with specific cell surface molecules in which case their proteolytic activity may be relatively localized. In addition, select MMPs, membrane type MMPs (MT-MMPs), possess a transmembrane domain, as do the related "a disintegrin and metalloproteinase(s)" or ADAMs. Of note, is that while named for their ability to target components of the extracellular matrix such as collagen and laminin, MMPs are increasingly recognized as effectors of non-matrix proteins. MMPs process soluble molecules including chemokines and cytokines, and they also target a variety of cell surface receptors and adhesion molecules.

MMPs are expressed in the CNS by a variety of cell types. It has been shown, for example, that astrocytes can release MMP-1, -2 and -3 , and that microglia can release MMP-7,-9 and -12 (Yong et al., 1998; Conant et al., 1999; Vos et al., 2000). Neurons may also release MMPs in the setting of excitotoxic injury (Szklarczyk et al., 2002; Meighan et al., 2006). MMPs are also released from activated monocytes and T cells, with monocytes releasing MMP-1,-7,-9 and -12, and T cells releasing abundant quantities of MMP-9. T cells also express MT1-MMP, which has proteolytic activity both in its membrane associated and shed extracellular domain form (Toth et al., 2005).

Of relevance to MS, MMPs have been well studied for their ability to cleave matrix proteins of the blood brain barrier and thus potentially facilitate the CNS ingress of inflammatory molecules and/or serum derived toxins (Anthony et al., 1998). MMPs have also been studied for their ability to cleave myelin basic protein (MBP) and myelin associated glycoprotein (Kieseier et al., 1999; Agrawal et al., 2008; Milward et al., 2008), and more recently, to generate immunogenic MBP peptides (Shiryaev et al., 2009). Of particular relevance to synaptic injury, however, is an emerging appreciation of MMPs as molecules that may be released proximal to the synapse (Sbai et al., 2008). A summary of relavant synaptic substrates is presented in Table 2 .

\section{MMPS CAN CLEAVE A VARIETY OF SYNAPTIC PROTEINS}

In terms of synaptic substrates, synaptic CAMs may be of particular relevance. Given what is known about MMP substrates in extra CNS sites, MMPs may be relatively efficient in terms of their ability to process such molecules. For example, MMPs have been well studied for their role in cell migration, and it is thus intuitive that processing of CAMs would play an important role in this process. Numerous studies support this possibility. For example, metalloproteinase mediated shedding of soluble ICAM-1 has been demonstrated (Lyons and Benveniste, 1998), and soluble ICAM-1 has been shown to promote smooth muscle cell migration (Lee et al., 2008).

Another important reason to focus on the potential for MMPs to mediate CAM cleavage in the setting of a disease that includes synaptic injury, however, lies in an abundance of evidence suggesting that CAMs are critical to synaptic structure and function (Sakurai et al., 1998). And though unrelated to synaptic injury per se, it is worth mentioning that CAM family members such as SynCAM4 might also mediate axon-glial interactions critical to processes including remyelination (Spiegel et al., 2007).

Synaptic CAMs have been shown to influence neuronal cell migration (Takeuchi and O'Leary, 2006), dendrite morphology (Tian et al., 2007), and the genesis/formation of the excitatory/inhibitory pre-synaptic complex (Biederer et al., 2002). Varied studies have also shown CAM integrity influences long term potentiation (LTP), a potential measure of learning and memory (Benson et al., 2000). It is therefore likely that metalloproteinase dependent processing of CAMs will likely have effects on both the formation and function of the synapse. In support of this possibility is a recent study which showed that ICAM-5 cleavage was linked to changes in dendrite morphology (Tian et al., 2007). This study was focused on MMP-2 and -9, MMPs which are elevated in MS as will be discussed in a section to follow. We also observed that varied MMPs could cleave ICAM-5 from hippocampal neurons, and that this could occur within 5 min of cell stimulation with NMDA (Conant et al., 2010). Rapid cleavage suggests that MMPs might be released from preformed neuronal stores to rapidly modulate synaptic protein integrity. 
Table 2 | Synaptic proteins that are processed by MMPs.

\begin{tabular}{|c|c|c|c|}
\hline Substrate & Protease & Relevance to synaptic structure/function & Reference(s) \\
\hline $\begin{array}{l}\text { Telencephalin/ } \\
\text { ICAM-5 }\end{array}$ & MMP-2, $-3,-7,-9$ & $\begin{array}{l}\text { Shedding is associated with changes in dendritic spine } \\
\text { morphology and may play a role in select forms of plasticity }\end{array}$ & Conant et al. (2010), Tian et al. (2007) \\
\hline NR2A & MMP-7 & Subunit of the NMDA type glutamate receptor & Szklarczyk et al. (2008) \\
\hline $\begin{array}{l}\text { Neuronal pentraxin } \\
\text { receptor (NPR) }\end{array}$ & ADAM-17 & $\begin{array}{l}\text { Ectodomain shedding allows an N terminal fragment to } \\
\text { surround and internalize AMPA type glutamate receptors, } \\
\text { thus contributing to synaptic plasticity/long term depression }\end{array}$ & Cho et al. (2008) \\
\hline Brevican & MMP-9 & $\begin{array}{l}\text { Structural stability of the synapse. Proteolytic cleavage has } \\
\text { been associated with synaptic loss }\end{array}$ & Yuan et al. (2002) \\
\hline Laminin- $\gamma 2$ & MT1-MMP & Structural stability of the synapse & Koshikawa et al. (2005) \\
\hline
\end{tabular}

ICAM-5 is but one of several synaptic CAMs that may be targeted by MMPs. For example, work from the laboratory of Patricia Maness has shown that MMPs can cleave NCAM (Hinkle et al., 2006), a molecule that may play a role in synapse formation (Muller et al., 2010). Others have shown that MMPs can process cadherins including $\mathrm{N}$-cadherin and E-cadherin (Monea et al., 2006). $\mathrm{N}$-cadherin has been linked to varied effects on the synapse. It can influence synaptic vesicle clustering (Stan et al., 2010), LTP (Tang et al., 1998; Bozdagi et al., 2000), and dendritic spine morphogenesis (Togashi et al., 2002). MMPs have also been shown to target synaptic dystroglycan (Michaluk et al., 2007), and though of less relevance to the CNS, agrin (VanSaun and Werle, 2000).

Though future studies will determine the extent to which MMPs target synaptic CAMs in MS and EAE, at least one study has shown that CAM levels may be reduced in the latter. This study showed that levels of NCAM-1 were reduced in CA1 and CA 3 regions of the hippocampus, while levels of MMPs -2 and -9 were increased in the same (Jovanova-Nesic and Shoenfeld, 2006).

While a variety of synaptic CAMs may be susceptible to MMP mediated proteolysis, additional synaptic proteins might be processed as well. For example, two studies have shown that MMPs can process the NR1 subunit of the $N$-methyl-D-aspartate (NMDA) type glutamate receptor (Pauly et al., 2008; Szklarczyk et al., 2008). These studies were focused on MMP-3 and -7, MMPs that have a relatively broad spectrum of substrates and that may be released by activated glia in the context of CNS inflammation. It was also shown that MMP-7 mediated cleavage of NR1 was associated with a reduction in NMDA stimulated calcium flux (Szklarczyk et al., 2008). In another study, it was shown that a transmembrane MMP could cleave neuronal pentraxin to affect an internalization of $\alpha$-amino-3-hydroxyl-5-methyl-4-isoxazole-propionate
(AMPA) receptor subunits (Cho et al., 2008). Thus, from these studies, MMPs might dampen glutamate transmission, something that could be protective in the setting of acute inflammation.

Additional synaptic modulators that may be processed by MMPs include $\mathrm{G}$ protein coupled receptors of the proteinase activated receptor family (Boire et al., 2005). Activation of these receptors follows from cleavage of the $\mathrm{N}$ terminus and the subsequent exposure of a tethered peptide ligand. These receptors are abundantly expressed on neurons (D'Andrea et al., 1998; Wang and Reiser, 2003) and their activation could potentially modulate synaptic structure and function.

\section{MMP-DEPENDENT PROCESSING OF SYNAPTIC SUBSTRATES PLAYS AN IMPORTANT ROLE IN NORMAL SYNAPTIC PHYSIOLOGY}

While a relatively new area of investigation, published studies suggest that MMPs may play a critical role in learning and memory. For example, a broad spectrum MMP inhibitor has been shown to reduce multiple forms of hippocampal CA1 plasticity (Meighan et al., 2007), and MMP-9 activity has been implicated in the maintenance of late LTP (Nagy et al., 2006). In addition, antisense to MMPs has been shown to prevent acquisition in the Morris water maze test (Meighan et al., 2006), and methamphetamine-induced behavioral sensitization is reduced in mice lacking MMP-2 or MMP-9 (Mizoguchi et al., 2007). Similarly, proteases have been shown to contribute to cocaine associated conditioned place preference (Brown et al., 2007, 2008; Maiya et al., 2009). In a more recent study, it was shown that a broad spectrum MMP inhibitor could prevent reconsolidation of a fear association memory that was not dependent on contextual cues (Brown et al., 2009). The mechanisms by which MMPs are important to learning and memory are as yet unclear, though we and others have suggested 
that the regulated processing of synaptic CAMs with subsequent effects on synaptic structure, likely plays a role (Tian et al., 2007; Conant et al., 2010).

\section{ELEVATED LEVELS OF MMPS MAY INTERFERE WITH MMP-DEPENDENT LEARNING, AND WHEN SUSTAINED, MAY CONTRIBUTE TO SYNAPTIC INJURY}

While physiological release of MMPs may enhance synaptic transmission, substantially elevated levels of these enzymes, as may occur with MS, might have different effects. Elevated levels might cause processes to which MMPs contribute, such as LTP, to go awry. In addition, high levels of MMPs might be neurotoxic. This latter possibility is supported by a variety of studies. For example, we have shown that high levels of MMP-1 were toxic to neurons in organotypic and dissociated cultures (Vos et al., 2000). Moreover, several investigators have shown that MMP-9 may be neurotoxic ( $\mathrm{Gu}$ et al., 2002; Jourquin et al., 2003; Thornton et al., 2008). In one study, recombinant MMP-9 caused pyramidal cell toxicity in hippocampal cultures (Jourquin et al., 2003). Published studies also suggest that the synapse may be vulnerable to MMP mediated toxicity. We noted that long term treatment of hippocampal neurons with MMP-7 led to a reduction in synaptic stability as determined by reductions in post-synaptic density length and terminal area (Szklarczyk et al., 2007a). And in a recent study of traumatic brain injury, it was noted that synapse loss, measured by reductions in synaptophysin, was prevented by an MMP inhibitor (Ding et al., 2009).

\section{VARIED MIMPS MAY BE ELEVATED IN ASSOCIATION WITH MS AND EAE}

Elevated levels of select MMPs, including MMP-2, 7, -9, and -12, have been detected in association with MS (Maeda and Sobel, 1996; Cossins et al., 1997; Lindberg et al., 2001; Vos et al., 2003; DiazSanchez et al., 2006), and elevated MMP levels have been correlated with disease severity and disability (Benesova et al., 2009). Elevated levels of MMPs including MMP-7 and MMP-9 have also been detected in EAE. In one study of adoptive transfer EAE, mRNA for MMP-7 was increased with maximum levels at peak disease. Levels of mRNA for MMP-9 were also elevated, while those of MMP-2 or -3 were not (Kieseier et al., 1998). The transcriptional expression of MMPs has also been examined in MS. In one study of post-mortem MS brain tissue by real-time polymerase chain reaction, it was noted that the mRNA expression of MMP-7 and -9 was upregulated throughout all stages of lesion formation with active inflammation (Lindberg et al., 2001). In this study, mRNA levels of while MMP-2,-3, and tumor necrosis factor (TNF)-alphaconverting-enzyme were not elevated. In a more recent study of mRNA in peripheral blood leukocytes from MS patients, MMP-7 and MT1-MMP were upregulated in relapsing remitting or chronic progressive patients as compared to controls. In this study, MMP-9 levels were not increased.

In work related to the question of whether MMPs are increased with MS, the possibility that polymorphisms influencing MMP expression may alter disease risk and/or severity has been examined. Fernandes and colleagues looked at the $\mathrm{C}^{-1562} \mathrm{~T}$ polymorphism, which leads to increased MMP-9 expression, in a large cohort of patients (165 MS, 191 controls) and found that the polymorphism was associated with increased disease severity as assessed by the
Expanded Disability Status Scale (Kurtzke, 1983; Fernandes et al., 2009). Increased $C^{-1562} \mathrm{~T}$ risk for MS was also noted in a recent Polish population study (Mirowska-Guzel et al., 2009).

\section{MMP INHIBITORS HAVE SHOWN PROMISE TOWARD MS TREATMENT}

Evidence from previously published studies suggests that overall, MMPs may play a detrimental role in MS. For example, TIMP-1 overexpression has been linked to a reduction in the infiltration of leukocytes as well as a reduced disease score on day 18 (Althoff et al., 2010). In related work, C57/Bl6 mice deficient in tissue inhibitor of metalloproteinases-1 (TIMP-1) show increased myelin pathology as compared to their wild type counterparts following MOG induced EAE (Crocker et al., 2006). Whether synaptic changes occurred and were also limited is unknown. Of interest, while TIMP-1 expression may typically increase in EAE and play a myelin protective role, TIMP-1 levels do not generally increase in MS (Crocker et al., 2006).

Studies using MMP inhibitors also suggest that these enzymes may contribute to disease pathology. For example, minocycline, an inhibitor that penetrates the brain and spinal cord, has been shown to suppress ongoing disease activity and to limit disease progression in a study that examined MOG immunized rats (Popovic et al., 2002). While minocycline has effects additional to the inhibition of MMP activity and expression, the authors noted that MMP-2 expression was increased in areas of inflammation in sham treated animals and that such expression was indeed reduced in minocycline treated animals (Popovic et al., 2002). They also pointed out that models of rheumatoid arthritis support the view that inhibition of MMP expression is at least in part responsible for the clinical efficacy of minocycline. Other animal studies also support a role for minocycline as a therapeutic agent. For example, when given in combination with glatiramer acetate or interferon- $\gamma$, minocycline therapy was associated with decreased inflammation, demyelination and axonal injury in MOG induced murine EAE (Giuliani et al., 2005a,b). In animal studies focused on particular MMPs, however, the situation is more complex. Studies suggest that while inhibition of family members including MMP-7 and -9 might benefit disease severity (Yong et al., 2007; Buhler et al., 2009), inhibition of MMP-12 might actually be detrimental (Weaver et al., 2005; Goncalves DaSilva and Yong, 2009). Thus, in the future it might be beneficial to design inhibitors that are somewhat selective (Yong et al., 2007).

Work from human studies also suggests that general inhibition of MMP activity might hold promise. A recent pilot study has demonstrated that minocycline could reduce gadolinium enhancing MRI lesions in MS within 2 weeks of treatment (Metz et al., 2004). Moreover, after 24 months of therapy, patients remained stable. In related work, estriol has been shown to reduce gadolinium enhancing lesions and to reduce levels of MMP-9 (Sicotte et al., 2002; Gold et al., 2009). In other work consistent with a role for MMPs in MS, interferon- $\beta$ (IFN- $\beta$ was shown to reduce MMP secretion and T cell migration (Leppert et al., 1996; Stuve et al., 1996). IFN therapy has also been linked to reduced peripheral blood mRNA for MMP-8, -9 and -19 (Bernal et al., 2009), and with decreased mRNA for MMP-7 in relapsing remitting, but not chronic progressive, patients (Galboiz et al., 2001). In a related study, IFN- $\beta$ was associated with an early and sustained ( 24 month) 
increase in TIMP-1 in MS patients classified as responders based on clinical criteria. Non-responders did not demonstrate this increase (Comabella et al., 2009).

In studies of inflammation related not to MS, but to spinal cord injury in mice, inhibition of MMP activity may also be of benefit. Of interest are findings suggesting that inhibition of MMP activity in the first 3 days following injury has benefit (Noble et al., 2002), while inhibition after this early period may actually hinder long term recovery (Trivedi, et al., 2005; Yong et al., 2007). One possibility is that injurious MMPs are particularly elevated at early time points while reparative MMPs are elevated at later time points (Hsu et al., 2006). Another non-mutually exclusive possibility is that particularly high levels of MMPs may be injurious while lower levels may be reparative. And finally, dynamics of the system as a whole may vary as a function of time after injury, and MMPs may in turn have a differential overall role that is dependent on these changes.

Whether the potential to inhibit cleavage of synaptic CAMs is involved in the protective effects of MMP inhibitors in MS and other inflammatory conditions of the CNS remains to be determined. Questions of timing and specificity with respect to particular MMPs will also need to be addressed. It is tempting to speculate, however, that MMP inhibitors would generally act to diminish synaptic changes that occur with inflammation.

\section{REFERENCES}

Agrawal, S. M., Lau, L., and Yong, V. W. (2008). MMPs in the central nervous system: where the good guys go bad. Semin. Cell Dev. Biol. 19, 42-51.

Althoff, G. E., Wolfer, D. P., Timmesfeld, N., Kanzler, B., Schrewe, H., and Pagenstecher, A. (2010). Long-term expression of tissue-inhibitor of matrix metalloproteinase- 1 in the murine central nervous system does not alter the morphological and behavioral phenotype but alleviates the course of experimental allergic encephalomyelitis. Am. J. Pathol. 177, 840-853.

Anthony, D. C., Miller, K. M., Fearn, S., Townsend,M.J., Opdenakker, G.,Wells, G. M., Clements, J. M., Chandler, S., Gearing, A. J., and Perry, V. H. (1998). Matrix metalloproteinase expression in an experimentally-induced DTH model of multiple sclerosis in the rat CNS. J. Neuroimmunol. 87, 62-72.

Audoin, B., Au Duong, M. V., Malikova, I., Confort-Gouny, S., Ibarrola, D., Cozzone, P. J., Pelletier, J., and Ranjeva, J.P. (2006). Functional magnetic resonance imaging and cognition at the very early stage of MS. J. Neurol. Sci. 245, 87-91.

Benesova, Y., Vasku, A., Novotna, H., Litzman, J., Stourac, P., Beranek, M., Kadanka, Z., and Bednarik, J. (2009). Matrix metalloproteinase- 9 and matrix metalloproteinase- 2 as biomarkers of various courses in multiple sclerosis. Mult. Scler. 15, 316-322.
Benson, D. L., Schnapp, L. M., Shapiro, L., and Huntley, G. W. (2000). Making memories stick: cell-adhesion molecules in synaptic plasticity. Trends Cell Biol. 10, 473-482.

Bernal, F., Elias, B., Hartung, H. P., and Kieseier, B. C. (2009). Regulation of matrix metalloproteinases and their inhibitors by interferon-beta: a longitudinal study in multiple sclerosis patients. Mult. Scler. 15, 721-727.

Biederer, T., Sara, Y., Mozhayeva, M., Atasoy, D., Liu, X., Kavalali, E. T., and Sudhof, T. C. (2002). SynCAM, a synaptic adhesion molecule that drives synapse assembly. Science 297, 1525-1531.

Boire, A., Covic, L., Agarwal, A., Jacques, S., Sherifi, S., and Kuliopulos, A. (2005). PAR1 is a matrix metalloprotease-1 receptor that promotes invasion and tumorigenesis of breast cancer cells. Cell 120, 303-313.

Bozdagi, O., Shan, W., Tanaka, H., Benson, D. L., and Huntley, G. W. (2000). Increasing numbers of synaptic puncta during late-phase LTP: $\mathrm{N}$-cadherin is synthesized, recruited to synaptic sites, and required for potentiation. Neuron 28, 245-259.

Brown, T. E., Forquer, M. R., Cocking, D. L., Jansen, H. T., Harding, J. W., and Sorg, B. A. (2007). Role of matrix metalloproteinases in the acquisition and reconsolidation of cocaine-induced conditioned place preference. Learn. Mem. 14, 214-223.

\section{CONCLUSIONS AND FUTURE DIRECTIONS}

MMPs levels may be substantially increased in association with MS. While these enzymes have been well studied for their ability to process proteins that contribute to blood brain barrier and myelin integrity, their potential to process synaptic proteins warrants additional investigation. MMP mediated cleavage of synaptic proteins may be adaptive or even protective in the setting of acute non-sustained inflammation, in that reduced synaptic function may limit neurotoxicity. Long-lived reductions in synaptic integrity might instead lead to irreparable synaptic damage. Alternatively, acute injury may be associated with particularly high and toxic levels of MMPs, while sustained but more moderate increases in MMP activity may instead promote neuronal process outgrowth and synaptic repair. If we are to design rational treatment strategies that would target MMPdependent events including synaptic proteolysis, we will need to know more regarding the question of whether, and when, these events are protective as opposed to injurious. We will also need to know more about the role of specific MMPs in these processes.

\section{ACKNOWLEDGMENTS}

This work was funded through the National Multiple Sclerosis Society, RG 4031A2/1

Brown, T. E., Forquer, M. R., Harding, J. W., Wright, J. W., and Sorg, B. A (2008). Increase in matrix metalloproteinase- 9 levels in the rat medial prefrontal cortex after cocaine reinstatement of conditioned place preference. Synapse 62, 886-889.

Brown, T. E., Wilson, A. R., Cocking, D. L., and Sorg, B. A. (2009). Inhibition of matrix metalloproteinase activity disrupts reconsolidation but not consolidation of a fear memory. Neurobiol Learn Mem 91, 66-72.

Buhler, L. A., Samara, R., Guzman, E. Wilson, C. L., Krizanac-Bengez, L., Janigro, D., and Ethell, D. W. (2009). Matrix metalloproteinase-7 facilitates immune access to the CNS in experimental autoimmune encephalomyelitis. BMC Neurosci. 10, 17.

Centonze, D., Bari, M., Rossi, S., Prosperetti, C., Furlan, R., Fezza, F., De Chiara, V., Battistini, L., Bernardi, G., Bernardini, S., Martino, G., and Maccarrone, M. (2007). The endocannabinoid system is dysregulated in multiple sclerosis and in experimental autoimmune encephalomyelitis. Brain 130, 2543-2553.

Centonze, D., Muzio, L., Rossi, S., Cavasinni, F., De Chiara, V., Bergami, A., Musella, A., D’Amelio, M., Cavallucci, V., Martorana, A., Bergamaschi, A., Cencioni, M. T., Diamantini, A., Butti, E., Comi, G., Bernardi, G., Cecconi, F., Battistini,
L., Furlan, R., and Martino, G. (2009). Inflammation triggers synaptic alteration and degeneration in experimental autoimmune encephalomyelitis. J. Neurosci. 29, 3442-3452.

Cho, R. W., Park, J. M., Wolff, S. B., Xu, D., Hopf, C., Kim, J. A., Reddy, R. C., Petralia, R. S., Perin, M. S., Linden, D. J., and Worley, P. F. (2008). mGluR1/5-dependent long-term depression requires the regulated ectodomain cleavage of neuronal pentraxin NPR by TACE. Neuron 57, 858-871.

Comabella, M., Rio, J., Espejo, C., Ruiz de Villa, M., Al-Zayat, H., Nos, C., Deisenhammer, F., Baranzini, S. E., Nonell, L., Lopez, C., Julia, E. Oksenberg, J. R., and Montalban, X. (2009). Changes in matrix metalloproteinases and their inhibitors during interferon-beta treatment in multiple sclerosis. Clin. Immunol. 130, 145-150.

Conant, K., McArthur, J. C., Griffin, D. E., Sjulson, L., Wahl, L. M., and Irani, D. N. (1999). Cerebrospinal fluid levels of MMP-2, 7, and 9 are elevated in association with human immunodeficiency virus dementia. Ann. Neurol. 46, 391-398.

Conant, K., Wang, Y., Szklarczyk, A., Dudak, A., Mattson, M. P., and Lim, S.T. (2010). Matrix metalloproteinasedependent shedding of intercellular adhesion molecule-5 occurs with 
long-term potentiation. Neuroscience 166, 508-521.

Cossins, J. A., Clements, J. M., Ford, J., Miller, K. M., Pigott, R., Vos, W., Van der Valk, P., and De Groot, C. J. (1997). Enhanced expression of MMP-7 and MMP-9 in demyelinating multiple sclerosis lesions. Acta Neuropathol. 94, 590-598.

Crocker, S. J., Whitmire, J. K., Frausto, R. F., Chertboonmuang, P., Soloway, P. D., Whitton, J. L., and Campbell, I. L. (2006). Persistent macrophage/ microglial activation and myelin disruption after experimental autoimmune encephalomyelitis in tissue inhibitor of metalloproteinase-1deficient mice. Am. J. Pathol. 169, 2104-2116.

D'Andrea, M. R., Derian, C. K., Leturcq, D., Baker, S. M., Brunmark, A., Ling, P., Darrow, A. L., Santulli, R. J., Brass, L. F., and Andrade-Gordon, P. (1998). Characterization of protease-activated receptor-2 immunoreactivity in normal human tissues. J. Histochem. Cytochem. 46, 157-164.

Diaz-Sanchez, M., Williams, K., DeLuca, G. C., and Esiri, M. M. (2006). Protein co-expression with axonal injury in multiple sclerosis plaques. Acta Neuropathol. 111, 289-299.

Ding, J. Y., Kreipke, C. W., Schafer, P., Schafer, S., Speirs, S. L., and Rafols, J. A. (2009). Synapse loss regulated by matrix metalloproteinases in traumatic brain injury is associated with hypoxia inducible factor-1alpha expression. Brain Res. 1268, 125-134.

Fernandes, K. S., Brum, D. G., Sandrim, V. C., Guerreiro, C. T., Barreira, A. A., and Tanus-Santos, J.E. (2009). Matrix metalloproteinase- 9 genotypes and haplotypes are associated with multiple sclerosis and with the degree of disability of the disease. J. Neuroimmunol. 214, 128-131.

Galboiz, Y., Shapiro, S., Lahat, N., Rawashdeh, H., and Miller, A. (2001). Matrix metalloproteinases and their tissue inhibitors as markers of disease subtype and response to interferonbeta therapy in relapsing and secondary-progressive multiple sclerosis patients. Ann. Neurol. 50, 443-451.

Giuliani, F., Fu, S. A., Metz, L. M., and Yong, V. W. (2005a). Effective combination of minocycline and interferonbeta in a model of multiple sclerosis. J. Neuroimmunol. 165, 83-91.

Giuliani, F., Metz, L. M., Wilson, T., Fan, Y., Bar-Or, A., and Yong, V.W. (2005b). Additive effect of the combination of glatiramer acetate and minocycline in a model of MS. J. Neuroimmunol. 158, 213-221.
Gold, S. M., Sasidhar, M. V., Morales, L. B., Du, S., Sicotte, N. L., TiwariWoodruff, S. K., and Voskuhl, R. R. (2009). Estrogen treatment decreases matrix metalloproteinase (MMP)-9 in autoimmune demyelinating disease through estrogen receptor alpha (ERalpha). Lab. Invest. 89, 1076-1083.

Goncalves DaSilva, A., and Yong, V. W. (2009). Matrix metalloproteinase-12 deficiency worsens relapsing-remitting experimental autoimmune encephalomyelitis in association with cytokine and chemokine dysregulation. Am. J. Pathol. 174, 898-909.

Gonzalez-Rosa, J. J., Vazquez-Marrufo, M., Vaquero, E., Duque, P., Borges, M., Gamero, M.A., Gomez, C. M., and Izquierdo, G. (2006). Differential cognitive impairment for diverse forms of multiple sclerosis. BMC Neurosci. 7, 39 .

Gu, Z., Kaul, M., Yan, B., Kridel, S. J., Cui, J., Strongin, A., Smith, J. W., Liddington, R. C., and Lipton, S. A. (2002). S-nitrosylation of matrix metalloproteinases: signaling pathway to neuronal cell death. Science 297, 1186-1190.

Hinkle, C. L., Diestel, S., Lieberman, J., and Maness, P. F. (2006). Metalloprotease-induced ectodomain shedding of neural cell adhesion molecule (NCAM). J. Neurobiol. 66, 1378-1395.

Hsu, J. Y., McKeon, R., Goussev, S., Werb, Z., Lee, J. U., Trivedi, A., and NobleHaeusslein, L. J. (2006). Matrix metalloproteinase-2 facilitates wound healing events that promote functional recovery after spinal cord injury. $J$. Neurosci. 26, 9841-9850.

Iimuro, Y., Nishio, T., Morimoto, T., Nitta, T., Stefanovic, B., Choi, S. K., Brenner, D. A., and Yamaoka, Y. (2003). Delivery of matrix metalloproteinase- 1 attenuates established liver fibrosis in the rat. Gastroenterology 124, 445-458.

Jourquin, J., Tremblay, E., Decanis, N., Charton, G., Hanessian, S., Chollet, A. M., Le Diguardher, T., Khrestchatisky, M., and Rivera, S. (2003). Neuronal activity-dependent increase of net matrix metalloproteinase activity is associated with MMP-9 neurotoxicity after kainate. Eur. J. Neurosci. 18, 1507-1517.

Jovanova-Nesic, K., and Shoenfeld, Y. (2006). MMP-2, VCAM-1 and NCAM-1 expression in the brain of rats with experimental autoimmune encephalomyelitis as a trigger mechanism for synaptic plasticity and pathology. J. Neuroimmunol. 181, 112-121.
Kieseier, B. C., Kiefer, R., Clements, J. M., Miller, K., Wells, G. M., Schweitzer, T., Gearing, A. J., and Hartung, H. P. (1998). Matrix metalloproteinase- 9 and -7 are regulated in experimental autoimmune encephalomyelitis. Brain 121(Pt 1), 159-166.

Kieseier, B. C., Seifert, T., Giovannoni, G., and Hartung, H. P. (1999). Matrix metalloproteinases in inflammatory demyelination: targets for treatment. Neurology 53, 20-25.

Kohutek, Z. A., diPierro, C. G., Redpath, G. T., and Hussaini, I. M. (2009). ADAM-10-mediated N-cadherin cleavage is protein kinase $\mathrm{C}$-alpha dependent and promotes glioblastoma cell migration. J. Neurosci. 29, 4605-4615.

Koshikawa, N., Minegishi, T., Sharabi, A., Quaranta, V., and Seiki, M. (2005). Membrane-type matrix metalloproteinase-1 (MT1-MMP) is a processing enzyme for human laminin gamma 2 chain. J. Biol. Chem. 280 88-93.

Kurtzke, J. F. (1983). Rating neurologic impairment in multiple sclerosis: an expanded disability status scale (EDSS). Neurology 33, 1444-1452.

Larsen, P. H., DaSilva, A. G., Conant, K. and Yong, V.W. (2006). Myelin formation during development of the CNS is delayed in matrix metalloproteinase- 9 and -12 null mice. J. Neurosci. 26, 2207-2214.

Lee, H. M., Kim, H. J., Won, K. J., Choi, W. S., Lee, K. Y., Bae, Y. M., Park, P. J., Park, T. K., Lee, Y. L., Lee, C. K., and Kim, B. (2008). Contribution of soluble intercellular adhesion molecule-1 to the migration of vascular smooth muscle cells. Eur. J. Pharmacol. 579, 260-268.

Lee, R., Kermani, P., Teng, K. K., and Hempstead, B. L. (2001). Regulation of cell survival by secreted proneurotrophins. Science 294, 1945-1948.

Leppert, D., Waubant, E., Burk, M. R., Oksenberg, J. R., and Hauser, S. L. (1996). Interferon beta-1b inhibits gelatinase secretion and in vitro migration of human $\mathrm{T}$ cells: a possible mechanism for treatment efficacy in multiple sclerosis. Ann. Neurol. 40, 846-852.

Lindberg, R. L., De Groot, C. J., Montagne, L., Freitag, P., van der Valk, P., Kappos, L., and Leppert, D. (2001). The expression profile of matrix metalloproteinases (MMPs) and their inhibitors (TIMPs) in lesions and normal appearing white matter of multiple sclerosis. Brain 124, 1743-1753.

Lu, X., Rong, Y., and Baudry, M. (2000). Calpain-mediated degradation of
PSD-95 in developing and adult rat brain. Neurosci. Lett. 286, 149-153.

Lyons, P. D., and Benveniste, E. N. (1998). Cleavage of membrane-associated ICAM-1 from astrocytes: involvement of a metalloprotease. Glia 22, 103-112.

Maeda,A., and Sobel, R.A. (1996). Matrix metalloproteinases in the normal human central nervous system, microglial nodules, and multiple sclerosis lesions. J. Neuropathol. Exp. Neurol. 55, 300-309.

Maiya, R., Zhou, Y., Norris, E. H., Kreek, M. J., and Strickland, S. (2009). Tissue plasminogen activator modulates the cellular and behavioral response to cocaine. Proc. Natl. Acad. Sci. U.S.A. 106, 1983-1988.

Meighan, P. C., Meighan, S. E., Davis, C. J., Wright, J. W., and Harding, J. W. (2007). Effects of matrix metalloproteinase inhibition on short- and long-term plasticity of schaffer collateral/CA1 synapses. J. Neurochem. 102, 2085-2096.

Meighan, S.E., Meighan, P.C., Choudhury, P., Davis, C. J., Olson, M. L., Zornes, P. A., Wright, J. W., and Harding, J. W. (2006). Effects of extracellular matrixdegrading proteases matrix metalloproteinases 3 and 9 on spatial learning and synaptic plasticity. J. Neurochem. 96, 1227-1241.

Metz, L. M., Zhang, Y., Yeung, M., Patry, D. G., Bell, R. B., Stoian, C. A., Yong, V.W., Patten, S. B., Duquette, P., Antel, J. P., and Mitchell, J. R. (2004). Minocycline reduces gadolinium-enhancing magnetic resonance imaging lesions in multiple sclerosis. Ann. Neurol. 55, 756.

Michaluk,P., Kolodziej,L., Mioduszewska, B., Wilczynski, G. M., Dzwonek, J., Jaworski, J., Gorecki, D. C., Ottersen, O. P., and Kaczmarek, L. (2007). Beta-dystroglycan as a target for MMP-9, in response to enhanced neuronal activity. J. Biol. Chem. 282, 16036-16041.

Milward, E., Kim, K. J., Szklarczyk, A., Nguyen, T., Melli, G., Nayak, M., Deshpande, D., Fitzsimmons, C., Hoke, A., Kerr, D., Griffin, J. W., Calabresi, P. A., and Conant, K. (2008). Cleavage of myelin associated glycoprotein by matrix metalloproteinases. J. Neuroimmunol. 193, 140-148.

Mirowska-Guzel, D., Gromadzka, G., Czlonkowski, A., and Czlonkowska, A. (2009). Association of MMP1, MMP3, MMP9, and MMP12 polymorphisms with risk and clinical course of multiple sclerosis in a Polish population. J. Neuroimmunol. 214, 113-117. 
Mizoguchi, H., Yamada, K., Mouri, A., Niwa, M., Mizuno, T., Noda, Y., Nitta, A., Itohara, S., Banno, Y., and Nabeshima, T. (2007). Role of matrix metalloproteinase and tissue inhibitor of MMP in methamphetamineinduced behavioral sensitization and reward: implications for dopamine receptor down-regulation and dopamine release. J. Neurochem. 102, 1548-1560.

Monea, S., Jordan, B. A., Srivastava, S., DeSouza, S., and Ziff, E. B. (2006). Membrane localization of membrane type 5 matrix metalloproteinase by AMPA receptor binding protein and cleavage of cadherins. J. Neurosci. 26, 2300-2312.

Muller, D., Mendez, P., De Roo, M., Klauser, P., Steen, S., and Poglia, L. (2010). Role of NCAM in spine dynamics and synaptogenesis. Adv. Exp. Med. Biol. 663, 245-256.

Nagy, V., Bozdagi, O., Matynia, A., Balcerzyk, M., Okulski, P., Dzwonek, J., Costa, R. M., Silva, A. J., Kaczmarek, L., and Huntley, G. W. (2006). Matrix metalloproteinase- 9 is required for hippocampal late-phase long-term potentiation and memory. J. Neurosci. 26, 1923-1934.

Noble, L. J., Donovan, F., Igarashi, T., Goussev, S., and Werb, Z. (2002). Matrix metalloproteinases limit functional recovery after spinal cord injury by modulation of early vascular events. J. Neurosci. 22, 7526-7535.

Pauly, T., Ratliff, M., Pietrowski, E., Neugebauer, R., Schlicksupp, A., Kirsch, J., and Kuhse, J. (2008). Activity-dependent shedding of the NMDA receptor glycine binding site by matrix metalloproteinase 3: a PUTATIVE mechanism of postsynaptic plasticity. PLoS ONE 3, e2681. doi:10.1371/journal. pone. 0002681 .

Popovic, N., Schubart, A., Goetz, B. D., Zhang, S. C., Linington, C., and Duncan, I. D. (2002). Inhibition of autoimmune encephalomyelitis by a tetracycline. Ann. Neurol. 51, 215-223.

Ranjeva, J. P., Audoin, B., Au Duong, M. V., Confort-Gouny, S., Malikova, I., Viout, P., Soulier, E., Pelletier, J., and Cozzone, P. J. (2006). Structural and functional surrogates of cognitive impairment at the very early stage of multiple sclerosis. J. Neurol. Sci. 245, 161-167.

Rossi, S., Furlan, R., De Chiara, V., Musella, A., Lo Giudice, T., Mataluni, G., Cavasinni, F., Cantarella, C., Bernardi, G., Muzio, L., Martorana, A., Martino, G., and Centonze, D. (2009). Exercise attenuates the clinical, synaptic and dendritic abnormalities of experimental autoimmune encephalomyelitis. Neurobiol. Dis. 36, 51-59.

Sakurai, E., Hashikawa, T., Yoshihara, Y., Kaneko, S., Satoh, M., and Mori, K. (1998). Involvement of dendritic adhesion molecule telencephalin in hippocampal long-term potentiation. Neuroreport 9, 881-886.

Sbai, O., Ferhat, L., Bernard, A., Gueye, Y., Ould-Yahoui, A., Thiolloy, S., Charrat, E., Charton, G., Tremblay, E., Risso, J. J., Chauvin, J. P., Arsanto, J. P., Rivera, S., and Khrestchatisky, M. (2008). Vesicular trafficking and secretion of matrix metalloproteinases-2, -9 and tissue inhibitor of metalloproteinases-1 in neuronal cells. Mol. Cell. Neurosci. 39, 549-568.

Schulz, D., Kopp, B., Kunkel, A., and Faiss, J. H. (2006). Cognition in the early stage of multiple sclerosis. J. Neurol. 253, 1002-1010.

Shiryaev, S. A., Savinov, A. Y., Cieplak, P., Ratnikov, B. I., Motamedchaboki, K., Smith, J.W., and Strongin, A. Y. (2009). Matrix metalloproteinase proteolysis of the myelin basic protein isoforms is a source of immunogenic peptides in autoimmune multiple sclerosis. PLoS ONE 4, e4952. doi:10.1371/journal. pone. 0004952 .

Sicotte, N. L., Liva, S. M., Klutch, R., Pfeiffer, P., Bouvier, S., Odesa, S., Wu, T. C., and Voskuhl, R. R. (2002). Treatment of multiple sclerosis with the pregnancy hormone estriol. Ann. Neurol. 52, 421-428.

Sorensen, T. L., and Ransohoff, R. M. (1998). Etiology and pathogenesis of multiple sclerosis. Semin. Neurol. 18, 287-294.

Spiegel, I., Adamsky, K., Eshed, Y., Milo, R., Sabanay, H., Sarig-Nadir, O., Horresh, I., Scherer, S. S., Rasband, M. N., and Peles, E. (2007). A central role for Necl4 (SynCAM4) in Schwann cellaxon interaction and myelination. Nat. Neurosci. 10, 861-869.

Stan, A., Pielarski, K. N., Brigadski, T., Wittenmayer, N., Fedorchenko, O., Gohla, A., Lessmann, V., Dresbach, T., and Gottmann, K. (2010). Essential cooperation of $\mathrm{N}$-cadherin and neuroligin-1 in the transsynaptic control of vesicle accumulation. Proc. Natl. Acad. Sci. U.S.A. 107, 11116-11121.

Stuve, O., Dooley, N. P., Uhm, J. H., Antel, J. P., Francis, G. S., Williams, G., and Yong, V. W. (1996). Interferon beta- $1 \mathrm{~b}$ decreases the migration of $\mathrm{T}$ lymphocytes in vitro: effects on matrix metalloproteinase-9. Ann. Neurol. 40, 853-863.

Szklarczyk, A., Conant, K., Owens, D. F., Ravin, R., McKay, R. D., and Gerfen,
C. (2007a). Matrix metalloproteinase-7 modulates synaptic vesicle recycling and induces atrophy of neuronal synapses. Neuroscience 149, 87-98.

Szklarczyk, A., Oyler, G., McKay, R., Gerfen, C., and Conant, K. (2007b). Cleavage of neuronal synaptosomalassociated protein of $25 \mathrm{kDa}$ by exogenous matrix metalloproteinase-7. $J$ Neurochem. 102, 1256-1263.

Szklarczyk, A., Ewaleifoh, O., Beique, J. C., Wang, Y., Knorr, D., Haughey, N., Malpica, T., Mattson, M. P., Huganir, R., and Conant, K. (2008). MMP-7 cleaves the NR1 NMDA receptor subunit and modifies NMDA receptor function. FASEB J. 22, 3757-3767.

Szklarczyk, A., Lapinska, J., Rylski, M., McKay, R. D., and Kaczmarek, L. (2002). Matrix metalloproteinase-9 undergoes expression and activation during dendritic remodeling in adult hippocampus. J. Neurosci. 22, 920-930.

Takeuchi, A., and O'Leary, D. D. (2006), Radial migration of superficial layer cortical neurons controlled by novel Ig cell adhesion molecule MDGA1. J. Neurosci. 26, 4460-4464.

Tang, L., Hung, C. P., and Schuman, E. M (1998). A role for the cadherin family of cell adhesion molecules in hippocampal long-term potentiation. Neuron 20, 1165-1175.

Thornton, P., Pinteaux, E., Allan, S. M., and Rothwell, N. J. (2008). Matrix metalloproteinase- 9 and urokinase plasminogen activator mediate interleukin-1-induced neurotoxicity. Mol Cell. Neurosci. 37, 135-142.

Tian, L., Stefanidakis, M., Ning, L., Van Lint, P., Nyman-Huttunen, H., Libert, C., Itohara, S., Mishina, M., Rauvala, H., and Gahmberg, C. G. (2007). Activation of NMDA receptors promotes dendritic spine development through MMP-mediated ICAM-5 cleavage. J. Cell Biol. 178, 687-700.

Togashi, H., Abe, K., Mizoguchi, A., Takaoka, K., Chisaka, O., and Takeichi, M. (2002). Cadherin regulates dendritic spine morphogenesis. Neuron 35, 77-89.

Toth,M.,Osenkowski,P., Hesek, D., Brown, S., Meroueh, S., Sakr, W., Mobashery, S., and Fridman, R. (2005). Cleavage at the stem region releases an active ectodomain of the membrane type 1 matrix metalloproteinase. Biochem. J. 387, 497-506.

Trapp, B. D., Peterson, J., Ransohoff, R. M., Rudick, R., Mork, S., and Bo, L. (1998). Axonal transection in the lesions of multiple sclerosis. N. Engl. J. Med. 338, 278-285.
Trapp, B. D., Wujek, J. R., Criste, G. A., Jalabi, W., Yin, X., Kidd, G. J.,Stohlman, S., and Ransohoff, R. (2007). Evidence for synaptic stripping by cortical microglia. Glia 55, 360-368.

Trivedi, A., Hsu, J. Y., Lin, Y., Goussev, S., Gan, J., Topp, K. S., and NobleHaeusslein, L. J. (2005). The effects of acute and extended inhibition of matrix metalloproteinases on demyelination and functional recovery after spinal cord injury. Int. J. Neuroprot. Neuroregener. 2, 30-30.

VanSaun, M., and Werle, M. J. (2000). Matrix metalloproteinase- 3 removes agrin from synaptic basal lamina. $J$. Neurobiol. 43, 140-149.

Vercellino, M., Plano, F., Votta, B., Mutani, R., Giordana, M. T., and Cavalla, P. (2005). Grey matter pathology in multiple sclerosis. J. Neuropathol. Exp. Neurol. 64, 1101-1107.

Vos, C. M., Sjulson, L., Nath, A., McArthur, J. C., Pardo, C. A., Rothstein, J., and Conant, K. (2000). Cytotoxicity by matrix metalloprotease-1 in organotypic spinal cord and dissociated neuronal cultures. Exp. Neurol. 163, 324-330.

Vos, C. M., van Haastert, E. S., de Groot, C. J., van der Valk, P., and de Vries, H. E. (2003). Matrix metalloproteinase-12 is expressed in phagocytotic macrophages in active multiple sclerosis lesions. J. Neuroimmunol. 138, 106-114.

Wang,H., and Reiser, G. (2003). Thrombin signaling in the brain: the role of protease-activated receptors. Biol. Chem. 384, 193-202.

Weaver, A., Goncalves da Silva, A., Nuttall, R. K., Edwards, D. R., Shapiro, S. D., Rivest, S., and Yong, V. W. (2005). An elevated matrix metalloproteinase (MMP) in an animal model of multiple sclerosis is protective by affecting Th1/Th2 polarization. FASEB J. 19, 1668-1670.

Wegner, C., Esiri, M. M., Chance, S. A., Palace, J., and Matthews, P. M. (2006). Neocortical neuronal, synaptic, and glial loss in multiple sclerosis. Neurology 67, 960-967.

Weiner, H. L. (2009). The challenge of multiple sclerosis: how do we cure a chronic heterogeneous disease? Ann. Neurol. 65, 239-248.

Williams, H., Johnson, J. L., Jackson, C. L., White, S. J., and George, S. J. (2010). MMP-7 mediates cleavage of $\mathrm{N}$-cadherin and promotes smooth muscle cell apoptosis. Cardiovasc. Res. 87, 137-146.

Yong, V. W., Agrawal, S. M., and Stirling, D. P. (2007). Targeting MMPs in acute and chronic neurological conditions. Neurotherapeutics 4, 580-589. 
Yong, V. W., Krekoski, C. A., Forsyth, P. A., Bell, R., and Edwards, D. R. (1998). Matrix metalloproteinases and diseases of the CNS. Trends Neurosci. 21, 75-80.

Yuan, W., Matthews, R. T., Sandy, J. D., and Gottschall, P. E. (2002). Association between protease-specific proteolytic cleavage of brevican and synaptic loss in the dentate gyrus of kainate-treated rats. Neuroscience 114, 1091-1101.
Zhu, B., Luo, L., Moore, G. R., Paty, D. W., and Cynader, M. S. (2003). Dendritic and synaptic pathology in experimental autoimmune encephalomyelitis. Am. J. Pathol. 162, 1639-1650.

Conflict of Interest Statement: The authors declare that the research was conducted in the absence of any commercial or financial relationships that could be construed as a potential conflict of interest.

Received: 15 June 2010; paper pending published: 28 June 2010; accepted: 13 August 2010; published online: 05 October 2010.

Citation: Szklarczyk A and Conant K (2010) Matrix metalloproteinases, synaptic injury, and multiple sclerosis. Front. Psychiatry 1:130. doi:10.3389/ fpsyt.2010.00130
This article was submitted to Frontiers in Neurodegeneration, a specialty of Frontiers in Psychiatry.

Copyright (c) 2010 Szklarczyk and Conant. This is an open-access article subject to an exclusive license agreement between the authors and the Frontiers Research Foundation, which permits unrestricted use, distribution, and reproduction in any medium, provided the original authors and source are credited. 